Prepared for the U.S. Department of Energy

under Contract DE-AC05-76RL01830

\title{
Nuclear Infrastructure Development: Strategies and Methods for Engaging States Seeking Nuclear Energy
}
SL Frazar
E Vergino
CA Kessler
J Essner
SJ Kreyling
RA Babcock
FA Morris
D Eipeldauer
CE Mathews
J Shipwash
M Bissani
KE Apt

January 2009

\section{Pacific Northwest}

NATIONAL LABORATORY

Proudly Operated by Battelle Since 1965 


\title{
DISCLAIMER
}

This report was prepared as an account of work sponsored by an agency of the United States Government. Neither the United States Government nor any agency thereof, nor Battelle Memorial Institute, nor any of their employees, makes any warranty, express or implied, or assumes any legal liability or responsibility for the accuracy, completeness, or usefulness of any information, apparatus, product, or process disclosed, or represents that its use would not infringe privately owned rights. Reference herein to any specific commercial product, process, or service by trade name, trademark, manufacturer, or otherwise does not necessarily constitute or imply its endorsement, recommendation, or favoring by the United States Government or any agency thereof, or Battelle Memorial Institute. The views and opinions of authors expressed herein do not necessarily state or reflect those of the United States Government or any agency thereof.

\author{
PACIFIC NORTHWEST NATIONAL LABORATORY \\ operated by \\ BATTELLE \\ for the \\ UNITED STATES DEPARTMENT OF ENERGY \\ under Contract DE-AC05-76RL01830
}

Printed in the United States of America
Available to DOE and DOE contractors from the Office of Scientific and Technical Information,
P.O. Box 62, Oak Ridge, TN 37831-0062;
ph: (865) 576-8401
fax: $(865)$ 576-5728
email: reports@adonis.osti.gov

\begin{abstract}
Available to the public from the National Technical Information Service, U.S. Department of Commerce, 5285 Port Royal Rd., Springfield, VA 22161 ph: (800) 553-6847 fax: $(703) 605-6900$ email: orders@ntis.fedworld.gov online ordering: http://www.ntis.gov/ordering.htm
\end{abstract}

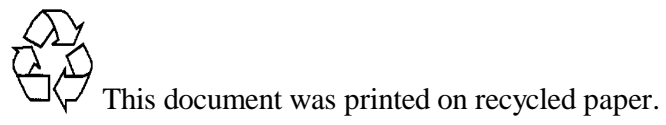




\section{Nuclear Infrastructure Development: Strategies and Methods for Engaging States Seeking Nuclear Energy}

Final Report on three DOE-NNSA Workshops:

Planning and Implementing Effective Infrastructure for Nuclear Energy Development:

Livermore, California January 14-16, 2008

Richland, Washington June 23-27, 2008

Expanding Nuclear Power to New States

Defining Needs and Exploring Paths to Success:

Como, Italy June 10-14, 2008

Prepared by Pacific Northwest National Laboratory with contributions from: Lawrence Livermore National Laboratory, Sandia National Laboratories, Oak Ridge National Laboratory, and Argonne National Laboratory

Final Report

Prepared for the Office of Global Security Engagement and Cooperation

The International Nuclear Safeguards and Engagement Program (NA-242) National Nuclear Security Administration John McClelland-Kerr, INSEP Team Lead

January 2009

Prepared for the U.S. Department of Energy under Contract DE-AC05-76RL01830

Pacific Northwest National Laboratory

Richland, Washington 99352 


\section{Table of Contents:}

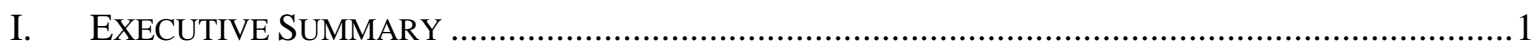

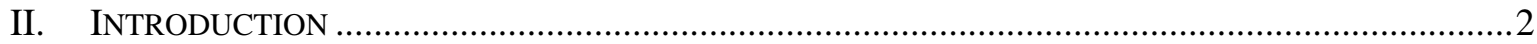

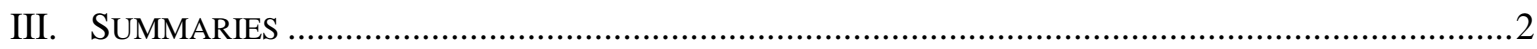

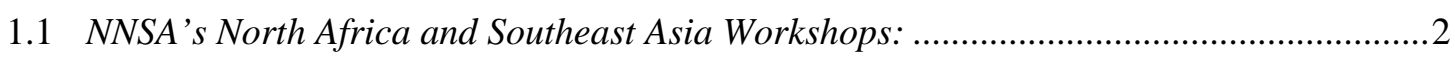

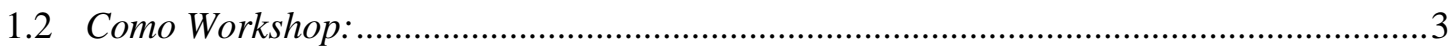

IV. WORKSHOP DISCUSSIONS, CONCLUSIONS, AND RECOMMENDATIONS ..................................4

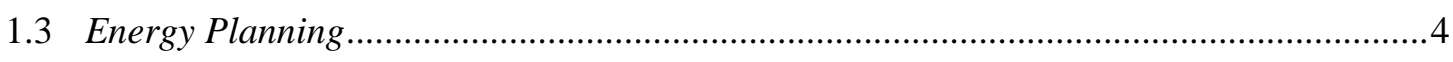

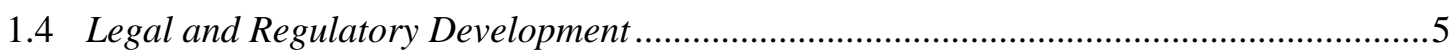

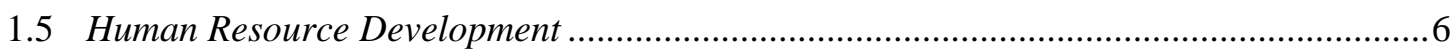

1.6 Safeguards, Safety and Security ............................................................................

1.7 Nuclear Fuel and Component Supply and Waste Management ........................................8

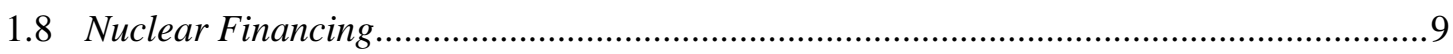

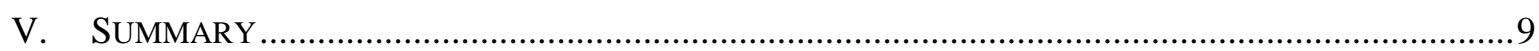





\section{EXECUTIVE SUMMARY}

In response to the anticipated worldwide nuclear renaissance, the United States Department of Energy (DOE) and its National Nuclear Security Administration (NNSA) sponsored three workshops in 2008 for countries considering developing nuclear energy programs. Two of the workshops were sponsored by NNSA in January and June for countries in North Africa and Southeast Asia, respectively, and focused on the safety, security and safeguards aspects of nuclear power development. With DOE and NNSA support, the Landau Network - Centro Volta in Como, Italy, hosted a third workshop in June that addressed a variety of topics ranging from nonproliferation to reactor financing, fuel services and waste management. ${ }^{1}$

The goal for all three workshops was to bring together experts, industry representatives and governmental officials to discuss important issues to be considered when developing nuclear power. Through these discussions, participants explored ideas for future collaboration and identified potential, but practical, scenarios for meeting national infrastructure needs. NNSA has pursued specific follow-on activities to these workshops with partners such as Jordan, Vietnam, Morocco and Thailand.

This report integrates the information collected during these workshops with impressions of workshop managers and provides nine recommendations for future collaboration. We view these workshops as successful mechanisms for engagement, but recognize that in some cases, participant views were not always clear or expressed; some participants may have simply recited views they thought we wanted to hear. Regardless, these workshops provided important information on participant needs, desires and attitudes toward developing nuclear power in their countries. While we have generated recommendations that we believe accurately reflect the needs of our partners, NNSA officials should re-evaluate them from time-to-time to ensure they remain relevant and meaningful. Moreover, NNSA should recognize that repeated exposure to international safeguards, safety and security best practices will help partners to achieve successful and sustainable nuclear power programs.

The following are considered high-priority recommendations and are ranked in order:

- Safeguards, Safety, and Security: Through bilateral and regional collaborative activities, NNSA should address safeguards, safety and security (and export control) topics together as they are part of an integrated system. In these efforts, NNSA should develop collaborative activities that explore the prioritization of infrastructure investments and reinforce the priority of developing safety and nonproliferation measures.

- Legislative and Regulatory Development: In coordination with the U.S. Nuclear Regulatory Commission and the International Atomic Energy Agency (IAEA), NNSA should develop realistic model safeguards and security regulatory guidance documents.

- Human Capacity Building: NNSA should partner with countries to help them develop and maintain qualified personnel capable of implementing safeguards, safety, security, laws, regulations, enforcement, and oversight and assist in defining elements of regional training centers of excellence focused on nonproliferation.

- Radioactive Waste Management: NNSA should work with partners to ensure that international best practices for radioactive waste management are adopted by new nuclear entrants. Special attention should be given to those countries interested in hosting regional or international radioactive waste repositories. (See the questionnaires included in the Como report identified in footnote 1.)

\footnotetext{
${ }^{1}$ The report on the June 2008 Como Workshop entitled: Report from Como: Expanding Nuclear Power to New States-Defining Needs and Exploring Paths to Success, is available at http://www.centrovolta.it/landau/CategoryView,category,WorkshopsAndEvents.aspx
} 


\section{INTRODUCTION}

Interest in nuclear power is increasing for countries seeking reliable sources of clean energy. Some fifty countries have announced their intentions to consider nuclear power and have requested assistance from the IAEA. Some have experience with nuclear power or have established capabilities that give them a start on nuclear power preparations. Others lack the technical infrastructure and expertise needed to develop, operate, regulate, and inspect a nuclear power program. The requests for assistance from these states are varied and numerous, ranging from how to develop the appropriate nuclear legislation and regulations for building a nuclear workforce.

As part of its efforts to support the safe, secure, and safeguarded expansion of nuclear power, the Department of Energy hosted three events in 2008. All three events were designed to address critical challenges associated with nuclear infrastructure development. The feedback and conclusions generated during these meetings provided NNSA with valuable insights on participant needs, expectations, and assumptions. Moreover, NNSA was able to use these workshops to strengthen its partnerships with countries in critical regions of the world and to identify opportunities for future collaboration.

Upon completion of the three events, the NNSA requested a full report detailing the discussions that took place, the conclusions and recommendations that were generated, and any lessons learned. Pacific Northwest National Laboratory (PNNL) prepared the report with contributions from its co-host for the two NNSA-sponsored workshops, Lawrence Livermore National Laboratory (LLNL), as well as inputs from Oak Ridge National Laboratory, Sandia National Laboratories, and Argonne National Laboratory. In the report that follows, the two NNSA workshops for North Africa and Southeast Asian countries will be presented first, followed by a description of the workshop in Como, Italy. Section IV provides additional details about the topics discussed during each workshop and a set of recommendations for follow-on activities pertaining to each topic.

\section{SUMMARIES}

\subsection{NNSA's North Africa and Southeast Asia Workshops:}

NNSA's International Nuclear Safeguards and Engagement Program (INSEP) sponsored the first infrastructure development workshop in Livermore, California, from January 14-17, 2008. Entitled "Planning and Implementing Effective Infrastructure for Nuclear Energy Development," this workshop brought together high-level nuclear and energy officials from Jordan, Morocco, Egypt, Tunisia and Algeria. Representatives from the IAEA, the U.S. Nuclear Regulatory Commission (NRC), Lawrence Livermore National Laboratory (LLNL), Pacific Northwest National Laboratory (PNNL), Argonne National Laboratory (ANL) and Texas A\&M University also participated in the event.

NNSA's INSEP sponsored a similar workshop in Richland, Washington, from June 23-27, 2008, for high level officials from several countries in Southeast Asia including Malaysia, Thailand, Indonesia, Vietnam, and the Philippines. Representatives from the IAEA, NRC, LLNL, PNNL, ANL, Oak Ridge National Laboratory (ORNL) and Sandia National Laboratories (SNL) also participated in the event.

Each workshop was designed to elaborate on the IAEA document Milestones in the Development of National Nuclear Power Infrastructure. ${ }^{2}$ Published in 2007, this document provides guidance in 19 topical areas to help countries meet three major milestones in the development of a nuclear power program: planning, constructing, and commissioning a reactor. The document is primarily a macro-level

${ }^{2}$ Milestones in the Development of National Nuclear Power Infrastructure. IAEA. 2007.

http://www-pub.iaea.org/MTCD/publications/PDF/Pub1305_web.pdf 
guidance document for countries pursing nuclear power for the first time, providing limited detail as to how to implement the guidance. ${ }^{3}$

In order to more fully explore the issues in the Milestones document, the workshops created a fictional country and simulation exercises to delineate the nuclear power development process for senior-level officials. Officials from the DOE, NRC, IAEA and DOE National Laboratories delivered presentations on various topics to facilitate discussions in the simulations. Topics presented included nuclear safeguards, security, nuclear safety, emergency management planning and response, waste management, and energy planning. The legal, regulatory, financial, and human resource challenges associated with each topic were explored as well. After each presentation, participants played the role of decision makers for the fictional country and were encouraged to consider the implications of key decisions associated with each topical area.

The group explored each issue through a simulated decision-making process associated with each topical area. The first topical area explored the energy planning process, focusing on the appropriate use of commissioned reports and energy planning studies. The next topical simulation turned to development of nuclear legislation and regulations, the role of an independent regulatory body and the obligations facing facility operators and other authorities in ensuring legislation is in place. One key part of this simulation was identifying the international treaties and conventions that the country could join as part of their commitment to safety, security, and nonproliferation. Participants then addressed the development of an effective safeguards system - including an effective State System of Accounting for and Control of Nuclear Material (SSAC). The succeeding simulations covered physical security requirements, safety and emergency response planning, and waste management. The development of human resources was addressed throughout the workshop as a cross-cutting issue affecting every aspect of the nuclear planning process. Although each topic was addressed individually, presenters highlighted significant interrelationships and interdependencies as appropriate.

Ultimately, the simulations highlighted the fictional country's strengths and deficiencies in each topical area, an exercise that provided some insight as to the participant country's own needs and capabilities in those areas. They also encouraged dialogue among partners in the region and helped us identify and implement specific follow-on activities. As a result, we believe these workshops represented a productive mechanism for engaging partners in nonproliferation areas. However, this assessment has a few caveats, which will be explained in section IV.

\subsection{Como Workshop: ${ }^{4}$}

DOE's Office of Nuclear Energy (NE) and NNSA's Office of Nonproliferation and International Security supported the third event, which was hosted by the Landau Network - Centro Volta, an NGO located in Como, Italy. Entitled "Expanding Nuclear Power to New States - Defining Needs and Exploring Paths to Success," this workshop was intended for current and emerging nuclear power states, nuclear experts and international organizations to discuss what could be done to facilitate expansion of nuclear power use while minimizing any new safety, security, and proliferation risks. This workshop was held at the Villa del Grumello, from June 10-14, 2008.

Fourteen delegates ${ }^{5}$ from eight countries and one regional Atomic Energy Agency interested in nuclear power joined 35 industry, government and nongovernment experts with a wide spectrum of nuclear

\footnotetext{
${ }^{3}$ Subsequent to the workshops, the IAEA published a follow-up Milestones document in 2008 entitled Evaluation of the Status of National Nuclear Infrastructure Development that contains more detail regarding the implementation process.

${ }^{4}$ The organizers of the Como Conference compiled a separate report, a copy of which can be found in Appendix A of this report.
} 
expertise in the conference. The conference's objective was to provide participants with the opportunity to discuss in an open, nongovernmental forum the perceived needs of states interested in developing or expanding nuclear power use and to consider what would be needed to implement nuclear power successfully, bearing in mind safety, security, and nonproliferation requirements.

During five days of presentations and discussion, participants explored a wide spectrum of topics including 1) the steps for successfully implementing a nuclear program; 2) options for large and small/medium size reactors; 3 ) possible constraints on the introduction or expansion of nuclear programs; 4) global nuclear energy partnerships and multilateral arrangements available for cooperation and to secure the supply of fuel; and 5) the costs, financial risks and funding prospects for nuclear power programs.

Nonproliferation and safeguards themes were woven through the presentations in ways that were subtle yet pervasive. The participants were surprised to learn that funding support had come from government organizations focusing on nonproliferation and safeguards. Participants noted they came away from the meeting with better insight into how they could participate in the nuclear renaissance and a better understanding of the advantages and challenges associated with nuclear power.

\section{WORKSHOP DISCUSSIONS, CONCLUSIONS, AND RECOMMENDATIONS}

Numerous ideas were raised in the workshops that can be valuable to planners and decision makers as they consider their development of nuclear power. However, as noted earlier, insights gained from discussions were sometimes overshadowed or limited by political sensitivities. During some discussions, one participant attending an NNSA workshop literally refused to contribute to the discussion, while others may have been stating views they thought we wanted to hear. In addition, we recognize that while participants express interest in implementing effective safety and nonproliferation measures, their primary concerns often focus on where they will obtain funds to construct their nuclear reactor or what supplier governments will require of them. For this reason, we view these workshops as part of an ongoing set of interactions with participants to understand their needs accurately and address them effectively. Overall, discussions were frank and revealing because we used a fictional country as a framework for discussion. NNSA should continue conducting workshops like these that focus primarily on safety and nonproliferation. It should also explore specific follow-on opportunities to demonstrate and reinforce how compliance with international safeguards, safety and security best practices can help partners achieve their goals and ensure broad international support for their program.

This section highlights key issues raised during discussions at all three events. Unless otherwise specified, each topical section reflects statements or conclusions common to all three events. Each section also provides conclusions and recommendations for next steps to facilitate continued engagement with the experts in these areas. The recommendations are not priority ranked but represent what we believe would be valuable for NNSA to undertake from the participant's standpoint in order to enable the safe and secure expansion of nuclear energy. A list of recommendations ranked in order of priority is provided in the Executive Summary.

\subsection{Energy Planning}

Understanding whether, when and how nuclear energy could fit into a nation's energy portfolio is a crucial first step towards establishing a nuclear power program. Once the political decision is made to

\footnotetext{
${ }^{5}$ These 14 delegates came from Argentina, Brazil, Jordan, Malaysia, Mexico, Namibia, Nigeria, Viet Nam, and the Arab Atomic Energy Agency. All are seriously considering the nuclear option as part of their energy mix, those that are preparing to acquire their first nuclear power plant (NPP), countries that are expanding their generation of nuclear electricity and those that are advanced in all the steps of the nuclear fuel cycle.
} 
pursue a nuclear power program, a country must take concurrent steps to understand the various obligations, regulations, and responsibilities that accompany such a decision. With that in mind, the workshops addressed a variety of energy planning issues, from which several challenges became apparent.

First, Como participants listed transmission capacity and efficiency as their greatest challenges. They recognized their decision to develop a nuclear program would depend on their ability to make the necessary investments to upgrade the electricity grid, but many indicated concern over their ability to expand and adapt their electrical infrastructure to include multiple nuclear power plants (NPPs). Experts at the conference introduced the concept of using smaller, 100 - 300 MWe reactors, rather than the 1000 - $1700 \mathrm{MWe}$ reactors currently being marketed as they offer opportunities for phased growth.

Participants lauded the value of such reactors and their intrinsic safety and safeguards measures but noted the technologies are not yet ready for commercial deployment. Their concerns, therefore, remain focused on upgrading their electrical grids in order to support the reactors available today.

Participants in NNSA's simulation exercises learned that gathering and accurately evaluating information on their national energy infrastructure is a critical capability that must be developed to facilitate effective decisions on future energy needs. Experts used a fictional consultant's report to address current overall power supply and demand situation, projected growth in electricity demand, the fuel and technology mix of the national power system, the current size and configuration of the grid, the economies of scale as they relate to reactor sizes and designs, and the cost of funding any necessary grid or other related infrastructure enhancements. The leaders were asked to assess if the evaluation was accurate and whether it provided the country with the information it needed to meet national energy demand and supply requirements. The exercise was designed to demonstrate that commissioned reports and other energy planning studies should not be used as the sole basis for making the decision to pursue nuclear power. Ultimately, the government or utility making the nuclear investment must have the capability to evaluate its own energy plans and make its decision to pursue nuclear power independently.

Recommendation 1: The IAEA and NNSA, in cooperation with DOE's NE, should continue to provide assistance with general energy planning and decision-making strategies. Regional workshops and bilateral training exercises should be designed to help countries understand the obligations and responsibilities associated with nuclear growth and encourage consideration of grid-sharing mechanisms in the region. Shared concern over the financing of nuclear power, the distribution of electricity in the region, and the issues of assured fuel supply and waste management services can often lead to discussions about ways to safeguard, secure and maintain shared reactors.

\section{$1.4 \quad$ Legal and Regulatory Development}

The regulatory and legislative mechanisms needed to govern a nuclear power program and industry are complex and often absent or undeveloped in countries pursuing nuclear power. The NNSA simulations highlighted the importance of establishing an independent nuclear regulator and provided information on the safety, security, and nonproliferation treaties and conventions countries could join as part of their commitment to a nuclear power program. In simulations, participants explored how to incorporate such legal instruments into national laws and regulations and implement their requirements.

Most of the participating countries have a nuclear regulatory body, but they typically have few staff members and regulate medical and industrial activities, radiation sources, and (in a few cases) research reactors. Rather than recreate the large regulatory body of advanced nuclear states like the United States, France, or Japan, participants requested case studies and realistic models to help guide them as they 
prepared appropriate legislative and regulatory bodies. Such models should reflect the regulatory bodies of mid-size states that regulate a few NPPs, such as Sweden, Finland, and Spain.

One factor emphasized during the workshop discussions was the length of time needed to join treaties, draft laws, and pass them through the legislative body. Participants discussed how the country's legislative and regulatory development process could affect the duration of the planning process or its implementation. Once the laws are established, nuclear regulations would have to be developed to clarify the roles and responsibilities of the state's facility operators and inspectors, thus further extending the planning and implementation process.

Presenters also highlighted the need for skilled personnel capable of filling critical positions early in the planning process. For instance, qualified experts would be needed to develop and enforce effective regulations and conduct inspections for the duration of the program. The participants explicitly highlighted their concern about developing such expertise and discussed their assumptions about how long it would take to develop an effective and internationally accepted legislative and regulatory framework, complete with adequately trained personnel. It's valuable to note that NNSA continues to respond to requests for assistance in preparing nuclear legislation and regulations subsequent to these workshops.

\section{Recommendation 2: In coordination with outreach provided by the U.S. Nuclear Regulatory Commission and the IAEA ${ }^{6}$, NNSA should continue and expand where possible support to states interested in enacting legislation and regulations necessary for a nuclear power program. Early engagement activities should focus on establishing an independent and effective nuclear regulatory body and developing personnel trained in regulatory development, enforcement, and inspections. To facilitate these interactions, NNSA should work with partners to develop realistic regulatory models for use as guides during the development process.}

\subsection{Human Resource Development}

A major issue dominating all three meetings was the availability (or the lack thereof) of sufficient human resources. Many countries lack individuals with skills at the appropriate technical and engineering level, who can fill critical nonproliferation positions. The shortage was particularly acute in the areas of licensing, construction, and operation of NPPs. Participants expressed concern that the expansion of nuclear power could create increasing competition for nuclear-related skills in the global market. In particular, they feared that promising young students who receive training abroad might not return home, seeking more lucrative international employment opportunities.

Participants expressed interest in establishing university programs and joining professional organizations such as the Institute for Nuclear Materials Management. Such efforts would help ensure reliable access to qualified scientists, engineers, regulators, planners, and technicians capable of implementing a nuclear power program that is in compliance with the international nonproliferation regime. They would also like to participate in specifically-tailored collaborations with members of the nuclear industry and other entities supporting the safe, secure, and safeguarded expansion of nuclear power, including the IAEA, the World Nuclear Association, World Nuclear University, the World Institute for Nuclear Security, the Nuclear Energy Agency, the Institute for Nuclear Materials Management, and the World Association of Nuclear Operators.

\footnotetext{
${ }^{6}$ The IAEA's Legislative Outreach Program, which is run out of the IAEA's Office of Legal Affairs, provides complementary assistance to Member States.
} 


\begin{abstract}
Recommendation 3: NNSA should work closely with countries to help them develop education and training programs that support a long-term cadre of personnel skilled in the areas of safeguards, safety, security, and laws and regulations. Such education and training programs should be designed for secondary and graduate level students, and current practitioners and trainers.
\end{abstract}

\title{
Recommendation 4: The NNSA should work with the IAEA and other international entities to foster regional partnerships that create centers of excellence. Regional training centers leverage resources and encourage host countries to take a leadership role in the region.
}

Finally, participants expressed concern over the most effective way to conduct public outreach. Typically, INSEP and NNSA do not engage in activities that involve public outreach since the goal of public outreach is to ostensibly promote nuclear power rather than implement nonproliferation best practices. However, public outreach is a major driver behind the development of strong safety, security, and safeguards measures, as governments must point to the development of these measures to alleviate concern about the plant's sustainability and reassure nervous citizens. Moreover, public campaigns to attract students towards science, technology, engineering, and math can help countries recruit skilled workers. Therefore, there is some value in working with counties on a limited basis to help them translate nonproliferation best practices into effective public outreach campaigns. In some cases, NNSA may need to pursue these types of activities as part of a broader package of assistance to countries to ensure the needs of both parties are being met.

\section{Recommendation 5: As part of a broader assistance package, NNSA should consider helping countries develop effective outreach programs that educate the public about nuclear power, recruit new students into the field - particularly in the areas that will require long-term preparation (e.g., safeguards and security) - and communicate the safety, security and effectiveness of the nuclear program to key stakeholders.}

\subsection{Safequards, Safety and Security}

Safeguards, safety, and security (the so-called " $3 \mathrm{~S}$ 's") are recognized internationally as critical components of an effective nuclear power program. Helping countries implement $3 \mathrm{~S}$ measures in ways that reinforce each other can significantly reduce the safety and proliferation risks associated with new nuclear power programs.

Safety: Experts in all three events noted that an accident in one nuclear power state could have repercussions on all states with nuclear power. An accident could hinder public acceptance of existing and planned nuclear plants in all states and prompt additional and costly regulations. Due to the time required to develop the necessary legal and regulatory frameworks governing safe operation of nuclear power reactors, participants agreed that safety should be addressed early.

Presenters discussed a variety of other safety-related issues. First, they noted that safety licensing and regulation takes five or more years, and an emergency plan, which can be complex, must be in place before beginning reactor operations at low power. The potential to build on existing response plans used by other industries was discussed as a means to reduce the effort. Second, presenters highlighted the importance of creating a safety culture, starting with the program's leadership and extending to individual staff members. Presenters emphasized that a safety-conscious work environment is one in which staff can raise safety concerns without fear of retribution. Cooperative training emerged as one of the best means to ensure a safety culture both domestically and internationally. Finally, presenters emphasized the importance of joining a liability convention such as the Convention on Supplementary Compensation for 
Nuclear Damage (CSC) to help allocate the legal and financial responsibility for managing a nuclear accident.

Security: Security was stressed because of the unique challenges presented by nuclear power and the attendant risks of sabotage, diversion, and proliferation. All participants seemed to be well aware of the proliferation risks associated with nuclear power programs and the need to employ every means necessary to reduce those risks. Presenters emphasized the importance of integrating safeguards and security measures in the prevention of proliferation and highlighted areas where the IAEA and NNSA can facilitate the development and implementation of such provisions.

Safeguards: The nuclear safeguards discussion was comprehensive, covering the history of the international safeguards regime and its contemporary components. All participants were aware of the nature of the safeguards regime, so discussion focused on the national responsibilities to ensure effective implementation. Presenters elaborated on how best to work with the IAEA and NNSA to develop and implement safeguards. Participants also discussed the importance of developing a training program in conjunction with legal and regulatory frameworks that supports safeguards and security as well as safety measures. For the most part, however, participant concerns centered on the prevention of accidents and sabotage rather than the theft or diversion of nuclear materials for illicit purposes.

In general, participants accepted that nuclear safety, security and safeguards are important issues that require immediate attention. However, when taken into consideration with other costly responsibilities, many may not agree that scarce resources should be invested in these areas. Future workshops should explore this issue in greater depth to understand more completely how countries intend to prioritize their investments and whether safeguards, safety and security are considered top priorities.

Recommendation 6: Through workshops, seminars and technical assistance activities, NNSA should pursue engagement by addressing topics as part of an integrated system. For instance, workshops on the legislative underpinnings of the Additional Protocol or UN Security Council Resolution 1540 enable NNSA to discuss safeguards, export controls and security as part of a system.

Recommendation 7: NNSA should develop collaborative activities that explore the prioritization of investments. NNSA must do more to understand its partners' concerns as they relate to the 3S's and evaluate how much priority they place on developing $3 S$ measures. Such evaluation will be critical to designing future assistance packages that link nonproliferation with partner priorities, if nonproliferation is not considered a top priority.

\subsection{Nuclear Fuel and Component Supply and Waste Management}

Como participants expressed significant interest in participating in the international fuel market. Some countries specifically noted their desire to develop indigenous fuel cycle capacity or even to host an international fuel fabrication plant that would contribute to the international market. Participants of the NNSA workshops, however, discussed the economic disadvantage of indigenous development of fuel cycle facilities for a small nuclear power program and expressed preference for options that encouraged cooperation on assured fuel supply options. It should be noted that while there is a heavy focus on international cooperation, participants indicated concern about becoming too dependent on assistance. The data from Como, while limited, suggests that participants want to pursue development of nuclear power with whomever they wish and on terms they negotiate.

Como participants also noted concerns about the nuclear supply chain. Some parts of the supply chain appear to be limited, such as the supply of heavy equipment used in nuclear and fossil-fired generating 
facilities (gas turbines, boilers, etc.). As the nuclear renaissance proceeds, some noted that there may also be a need for vendors and governments to address new capabilities to manufacture reactor pressure vessels, rotors for turbine generators, and large power transformers.

Finally, participants in all three meetings discussed issues related to radioactive waste management and waste disposal. Como participants discussed technical options for the ultimate geological isolation of conditioned wastes. Participants expressed concern over the environmental issues associated with nuclear waste; the costs and benefits of waste management; and how these should be assessed for each storage and disposal option. On the whole, the attendees understood the challenges posed by large volumes of nuclear waste and seemed eager to consider different waste disposal options. Como participants specifically discussed the potential of using international geological repositories to store nuclear waste.

Recommendation 8: NNSA should work with partners and other DOE offices to ensure that international best practices for radiological waste management are adopted by nuclear developing countries. Special attention should be given to identifying specific countries that might be interested in hosting global radioactive waste repositories, with a view to determining what they might want in relation to financial benefits and legally-binding arrangements.

\section{$1.8 \quad$ Nuclear Financing}

All three events explored the economic factors and risks involved in deciding to implement a nuclear power program. Specifically, the simulation workshops focused on identifying some of the unanticipated costs associated with implementing a nuclear power program, such as funding the development of laws, regulations, SSACs, human resources, electrical grid improvements, materials, and equipment.

Meanwhile, Como participants discussed the option of collecting revenues from the operating power plant to pay back financiers and selling excess energy to retire investment debt. All three meetings noted that financing a nuclear program in smaller countries can pose a significant burden, and regional power sharing arrangements may be one mechanism for lowering the cost to each individual state while enhancing power supply reliability and potentially regional security.

Recommendation 9: The NNSA should stay abreast of financing issues for nuclear power program development and coordinate international technical assistance programs with DOE's NE. To avoid duplication of activities, NNSA's assistance activities should focus primarily on providing information about the financial obligations associated with developing $3 S$ infrastructures.

\section{SUMMARY}

Collaborations with nuclear aspirants on activities that promote nuclear safety and nonproliferation will continue to demand significant resources from the United States. Although we are learning more about our partners' needs and concerns with each collaborative activity, our knowledge of their capabilities and priorities remains imprecise. To ensure future resources are allocated cost-effectively, DOE/NSNA must evaluate the lessons learned from workshops like those presented in this report to determine accurately the nature of our partners' needs and the best mechanisms for meeting them. As noted in this report, some of those mechanisms exist while others have yet to be developed. And sometimes, partners' needs will not always relate to NNSA's nonproliferation objectives. With this in mind, it is important to start planning specifically-targeted engagements that better address our partners' interests while reinforcing NNSA's nonproliferation objectives. Such work may require cooperation with other offices within the U.S. Government, DOE, NNSA and NA-24. Although the coordination of such activities may prove to be complex, the outcome of a unified approach to assisting countries in developing effective nuclear infrastructures will be more desirable and cost-effective in the long-term. 